\title{
A new phosphatized ophiuroid from the lower Triassic of Nevada and its position in the evolutionary history of the Ophiuroidea (Echinodermata)
}

\author{
BEN THUY ${ }^{1 *}$, VIVIENNE MAXWELL ${ }^{2} \&$ SARA B. PRUSS ${ }^{2}$ \\ ${ }^{I}$ Natural History Museum Luxembourg, Department of Paleontology, 25 rue Münster, 2160 Luxembourg City, Luxembourg. \\ ${ }^{2}$ Department of Geosciences, Smith College, Northampton, MA 01063, USA. \\ ”"vmaxwell@smith.edu; 이ttps://orcid.org/0000-0002-2597-0498 \\ ”"spruss@smith.edu; ○ https://orcid.org/0000-0003-1751-2697 \\ *corresponding author: इ"bthuy@mnhn.lu; @ https://orcid.org/0000-0001-8231-9565
}

\begin{abstract}
The Lower Triassic fossil record of brittle stars is relatively rich, yet most records published to date are based on poorly preserved or insufficiently known fossils. This hampers exhaustive morphological analyses, comparison with recent relatives or inclusion of Early Triassic ophiuroid taxa in phylogenetic estimates. Here, we describe a new ophiuroid from the Lower Triassic of Nevada, preserved as phosphatized skeletal parts and assigned to the new taxon Ophiosuperstes praeparvus gen. et sp. nov Maxwell, V. \& Pruss. S.B. This unusual preservation of the fossils allowed for acid-extraction of an entire suite of dissociated skeletal parts, including lateral arm plates, ventral arm plates, vertebrae and various disk plates, thus unlocking sufficient morphological information to explore the phylogenetic position of the new taxon. Bayesian phylogenetic inference suggests a basalmost position of $O$. praeparvus within the Ophintegrida, sister to all other sampled members of that superorder. The existence of coeval but more derived ophiuroids suggests that $O$. praeparvus probably represents a member of a more ancient stem ophintegrid group persisting into the Early Triassic.
\end{abstract}

Key words: brittle star, end-Permian mass extinction, phylogeny, fossil

The Late to Early Triassic was a pivotal interval in the evolution of marine communities (e.g. Brayard et al. 2017). It witnessed the most extensive mass extinction event so far recorded in Earth history (Sepkoski 1981; Erwin 1993). As a consequence, many of the surviving organismal clades are believed to have undergone a drastic bottleneck followed by a post-extinction radiation (e.g. Twitchett \& Oji 2005). However, our understanding of the evolutionary change associated with the end-Permian mass extinction and the subsequent recovery directly depends on the completeness of the fossil record available. In recent years, a number of new fossil discoveries have challenged previous paradigms on faunal change around the Permian-Triassic boundary, including an unexpectedly rapid postPermian recovery of some marine groups (Brayard et al. 2017; Doguzhaeva et al. 2018; Botting et al. 2019; Brayard et al. 2019b; Charbonnier et al. 2019; Romano et al. 2019; Saucède et al. 2019) and the previously unnoticed survival of Paleozoic holdovers (Thuy et al. 2017; Thompson et al. 2018; Hagdorn 2018).

Ophiuroids, or brittle stars, are one of the five extant echinoderm classes to have survived the end-Permian mass extinction. With respect to their Late to Early Triassic fossil record, they appear to be the best sampled of the five classes, with more than 14 species known from around the boundary interval (Chen \& McNamara 2006). A critical re-evaluation of these fossil occurrences, however, debunked most of them as poor, based on insufficiently preserved specimens and/or superficial descriptions, thus precluding their inclusion in phylogenetic analyses (Thuy et al. 2019). In fact, for an ophiuroid fossil to be available for phylogenetic studies, it has to be known in sufficient detail to allow comparison with recent relatives (Thuy \& Stöhr 2016). The lack of phylogenetically informative ophiuroid fossils from the Late to Early Triassic is particularly unfortunate because the current consensus on the evolution of the class indicates a mid-Permian origin for the crown-group Ophiuroidea followed by a rapid radiation of the major extant clades (O'Hara et al., 2014, 2017; Thuy \& Stöhr 2016, 2018).

Here, we describe new ophiuroid fossils from the Lower Triassic of Nevada (Fig. 1). The extraordinary preservation of the fossils, involving replacement of the original skeletal calcite by calcium phosphate (apatite), 
allowed for acid-extraction of an entire suite of dissociated skeletal plates from limestone, unlocking sufficient morphological information to allow inclusion of the new ophiuroid in a phylogenetic analysis.

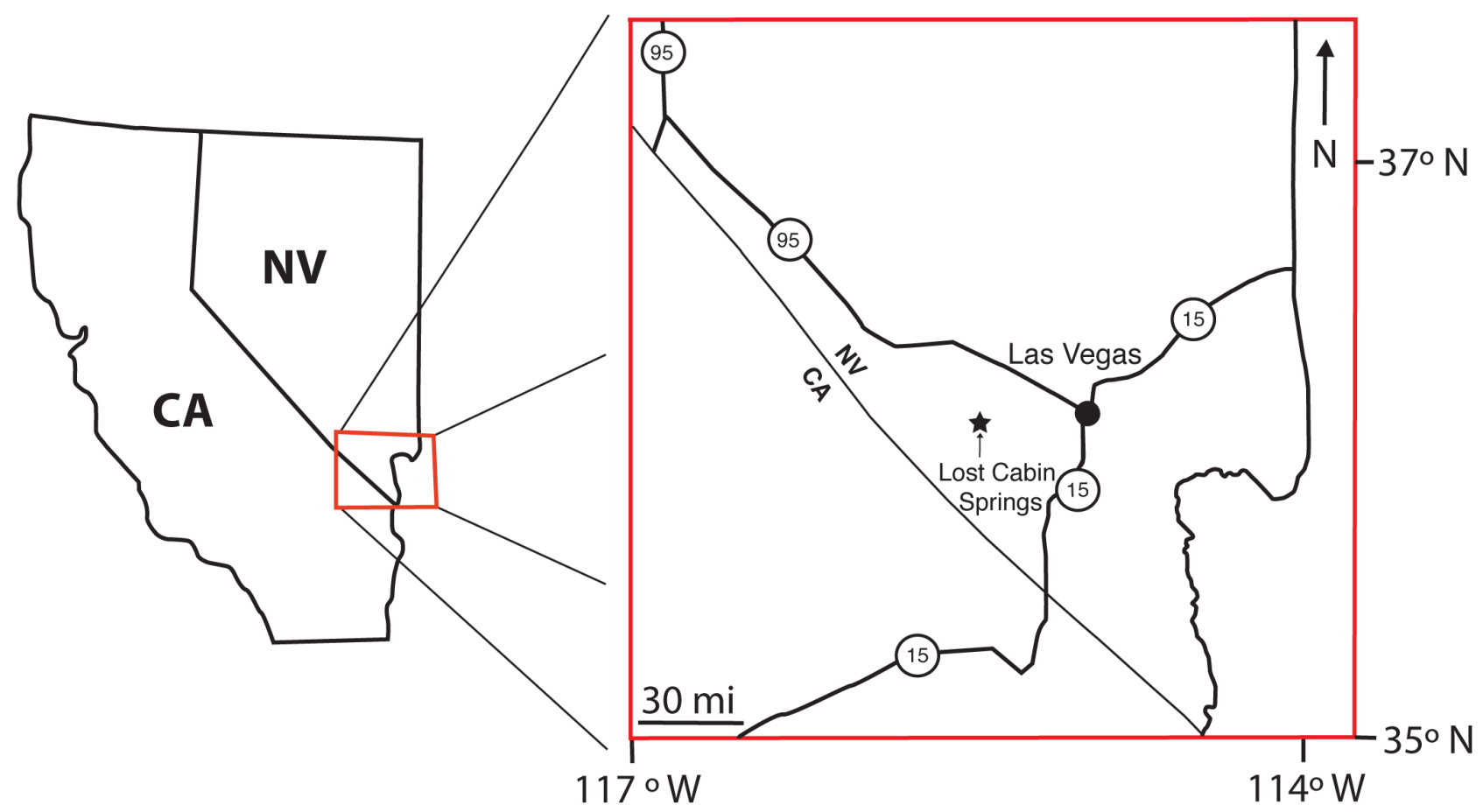

FIGURE 1: Locality map of the Virgin Limestone Member at the Lost Cabin Springs Locality, Southern Nevada, Western United States $\left(36^{\circ} 4^{\prime} 57.18^{\prime} \mathrm{N}, 115^{\circ} 39^{\prime} 12.05^{\prime} \mathrm{W}\right.$ is near the base of the section). (modified from Maxwell, 2020).

\section{Geological Context}

During the Early Triassic, the western United States was situated at a tropical paleolatitude (Reif \& Slatt, 1979). The Lower Triassic Moenkopi Formation extends throughout the Colorado Plateau and into southern Nevada and its depositional environment gradually shifts from continental fluvial sedimentation in Arizona to more intertidal and shallow marine environments in Utah and Nevada (Reif \& Slatt, 1979). The Moenkopi Formation in southern Nevada was deposited in a shallow water setting on the eastern margin of the Panthalassa sea (Marzolf, 1993) (Fig. 2). The non-marine Timpoweap Member or the Lower Red Member is overlain by the Virgin Limestone Member, which is in turn overlain by the evaporitic Shnabkaib Member (Reif \& Slatt, 1979). The Virgin Limestone Member of the Moenkopi Formation is a mixed carbonate-siliciclastic succession (Poborski, 1953). At the Lost Cabin Springs locality, it is constrained to the Spathian Stage (late Early Triassic) (Poborski, 1953) and was deposited in a stormdominated subtidal paleoenvironment (Schubert \& Bottjer, 1995; Pruss et al., 2005). There is an abundance of unusual facies present in the Virgin Limestone Member, including microbialite facies, such as large microbial reef mounds that span the length of the Lost Cabin Springs outcrop area (Pruss \& Bottjer, 2004), wrinkle structures (Pruss et al., 2004), and flat-pebble conglomerate facies (Pruss et al., 2005). Of eight fossiliferous samples, ophiuroids were only present in Bed LC-18-34 (Maxwell et al., 2020). Approximately 115 meters from the base, this bed is a thin $3.5 \mathrm{~m}$-thick fossiliferous packstone with isolated crinoidal ossicles overlying a small microbial build-up.

\section{Material and Methods}

In 2018 and 2019, samples of fossiliferous packstone were collected and dissolved in $200-400 \mathrm{ml}$ of $10 \%$ glacial acetic acid solution buffered with ammonium acetate, and only one sample (LC-18-34) produced abundant ophiuroid fragments. The insoluble residues were sieved into the following size fractions: $>400 \mu \mathrm{m},>250 \mu \mathrm{m}$ and $>177 \mu \mathrm{m}$, and the ophiuroid elements were common components of the $>400 \mu \mathrm{m}$ and $>250 \mu \mathrm{m}$ fractions. The sieved samples were examined under the Nikon SMZ645 stereoscopic microscope, and an Olympus BHS BH-2 light microscope 
was used to image these fossils. The best preserved ophiuroid elements $(\mathrm{n}=71)$ were coated with gold and palladium by a Hummer V Sputter coater and imaged with the FEI Quanta 450 Scanning Electron Microscope (SEM) at Smith College and with the Jeol Neoscope JMC-5000 SEM at the Natural History Museum Luxembourg. The elemental composition of the fossils was analyzed using EDS (Energy Dispersive Spectroscopy) Team software at Smith College.

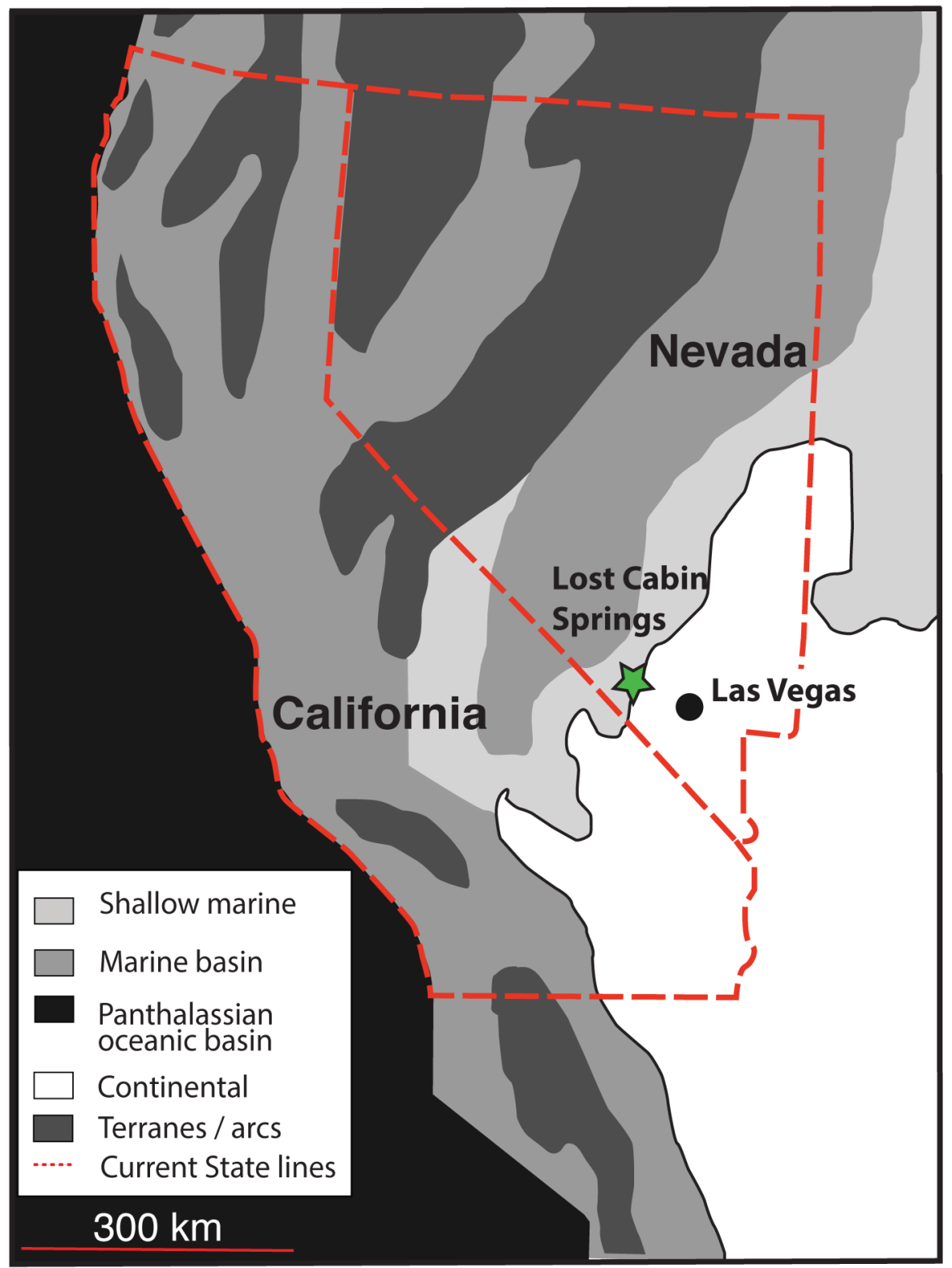

FIGURE 2: Early Triassic paleogeographic reconstruction of the western US. The Lost Cabin Springs Locality is denoted with a green star and the various shades depict the depositional environment during the Early Triassic (modified from Hoffmann et al., 2013).

Specimens here included were deposited in the collections of the Natural History Museum (MnhnL OPH) and the Muschelkalkmuseum Ingelfingen (MHI).

The terminology used herein follows Stöhr et al. (2012) and Thuy \& Stöhr $(2011,2016)$. We adopt the classification proposed by O'Hara et al. $(2017,2018)$. The extreme fragility of the skeletal plates, however, precluded detachment and re-mounting of the lateral arm plates. As a result, we were unable to illustrate the external and internal sides of the same lateral arm plates using scanning electron microscopy, as is a common practice in ophiuroid descriptions (Thuy \& Numberger-Thuy 2021).

We scored the skeletal plates following Thuy \& Stöhr (2016, 2018), referring to the same character definitions and acronyms and using the character matrix elaborated by Thuy \& Stöhr (2016) and modified by Thuy \& Stöhr 
(2018) but excluding Inexpectacantha acrobatica Thuy, 2005 because of its ambiguous taxonomic affinities (Thuy \& Numberger-Thuy 2021). The character matrix including the scores of the ophiuroid material described in the present paper is shown in Table 1. Bayesian inference analysis was performed using MrBayes (Huelsenbeck \& Ronquist 2001) which relies on a modified version of the Juke-Cantor model for morphological data as outlined by Lewis (2001), with variable character states from 2 to 10 (Wright \& Hillis 2014). Only variable characters were sampled, and we compensated for character selection bias by letting MrBayes search for parsimony informative characters (Mkpars model) (Wright \& Hillis 2014). All character states were assumed to have equal frequency, and prior probabilities were equal for all trees. We assumed that evolutionary rates vary between sites according to a discrete gamma distribution. Average standard deviations of split frequencies stabilized at about 0.008 after 3 million generations (mgen), sampled every 1,000 generations. The first $25 \%$ of the trees were discarded as burnin. The consensus trees were examined with the software FigTree v. 1.4.2 by Rambaut (http://tree.bio.ed.ac.uk/software/ figtree/). Confidence intervals of $95-99 \%$ were regarded as strong support for a node to be true, and at least $90 \%$ probability as good support.

\section{Results}

\section{Preservation of the ophiuroid remains}

The ophiuroid fragments described herein were found in insoluble residues of one packstone sample (LC-1834). The insoluble residues from this sample were dominated by ophiuroid fragments with very few other fossils preserved. The most abundant fragments in this sample were vertebrae, which were brown to amber in color. These were all likely preserved as stereomic molds, with minerals infilling and replacing parts of the skeletal elements, so the stereomic structure is well preserved and visible in SEM imagery.

\section{Phylogenetic analysis}

The Bayesian estimate resulted in a well-resolved tree (Fig. 3) with good support for most of the clades. The ophiuroid taxon described herein (Ophiosuperstes praeparvus gen. et sp. nov.) holds a basal position in the tree, sister to the Ophintegrida clade. This node gains high posterior probability ( $96 \%$ ), suggesting a robust phylogenetic relationship. The Ophintegrida clade is almost fully resolved, including a basal split into an Ophiacanthida-Ophioscolecida clade (but including the Ophioleucida) and an Amphilepidida clade. The other Triassic ophiuroid included in the tree, Aplocoma agassizi, holds a more derived position than Ophiosuperstes praeparvus, being situated at the base of the Ophiodermatina.

\section{Systematic palaeontology}

Class Ophiuroidea Gray, 1840

Subclass Myophiurida Matsumoto, 1915

Infraclass Metophiurida Matsumto, 1913

Superorder Ophintegrida O’Hara, Hugall, Thuy, Stöhr \& Martynov, 2017

\section{Order unknown}

\section{Family unknown}

Genus Ophiosuperstes nov. 


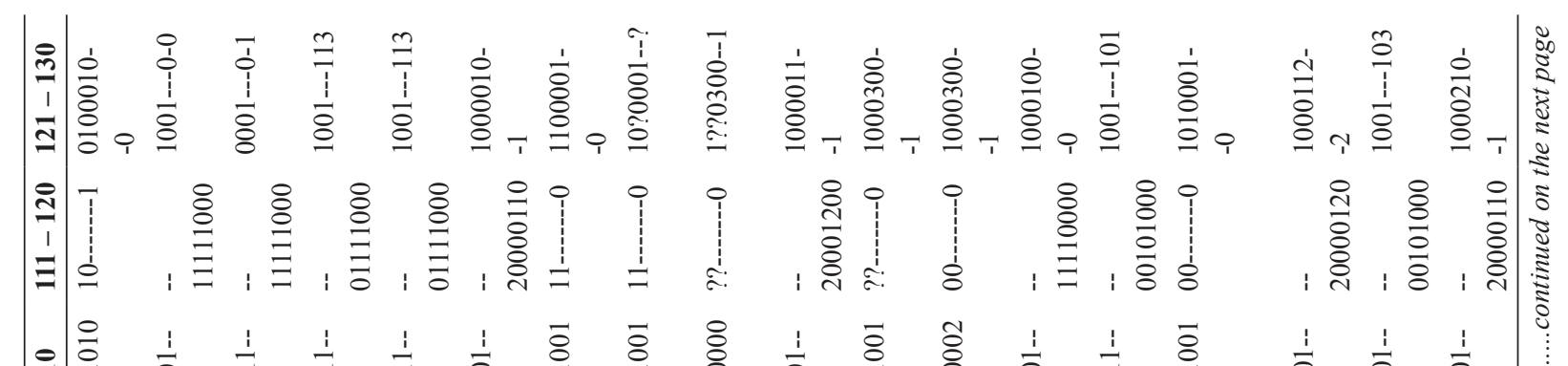

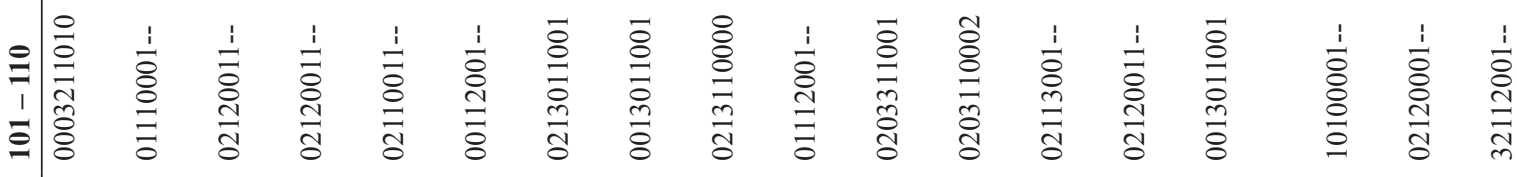

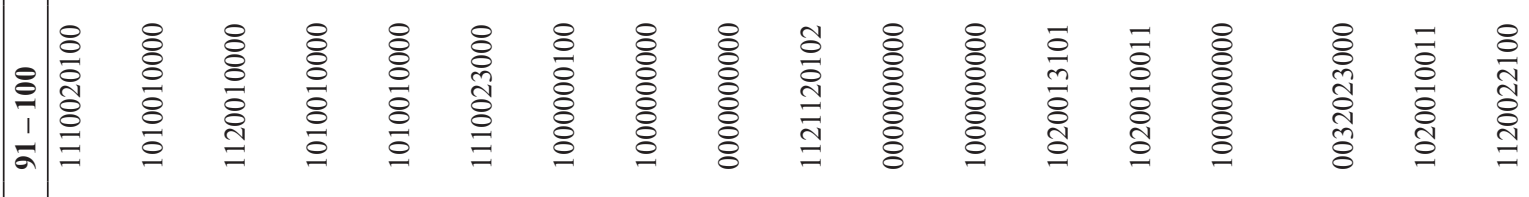

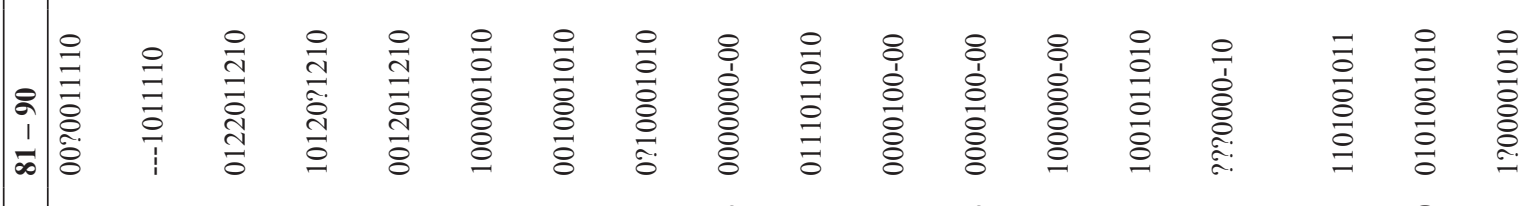

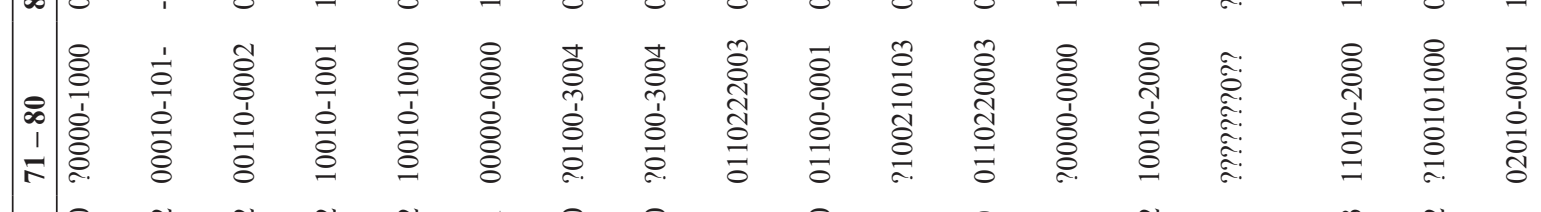

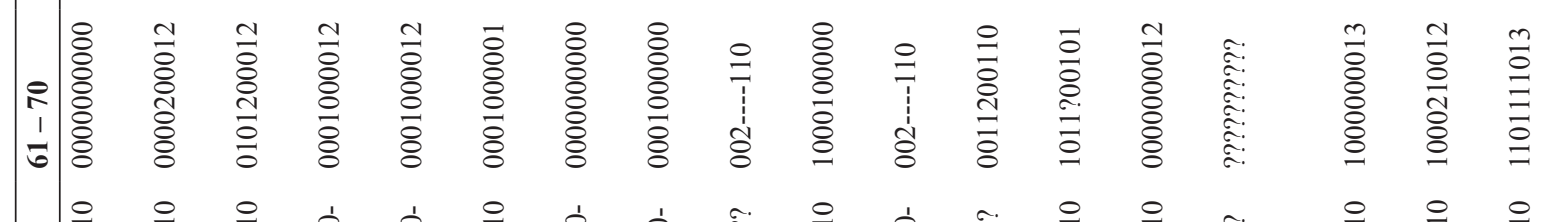

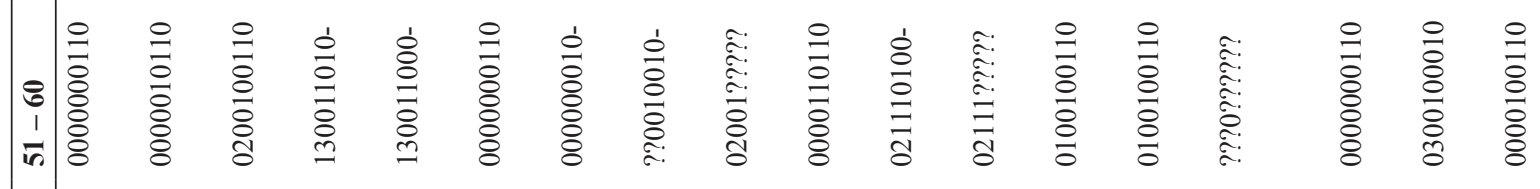

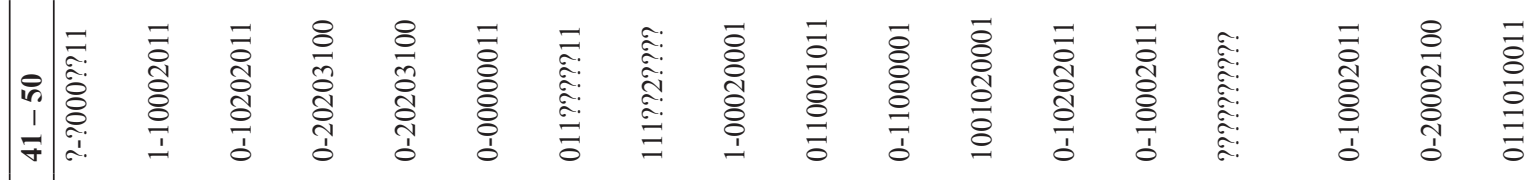

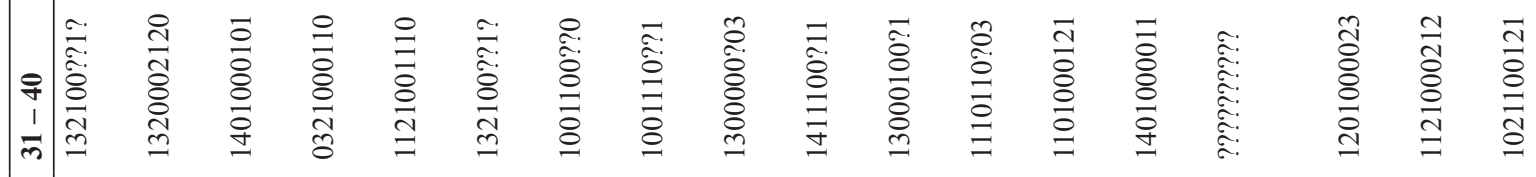

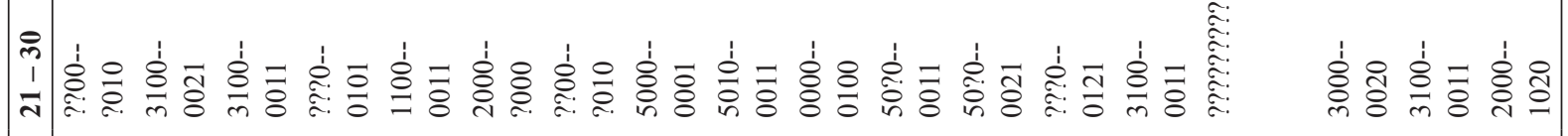

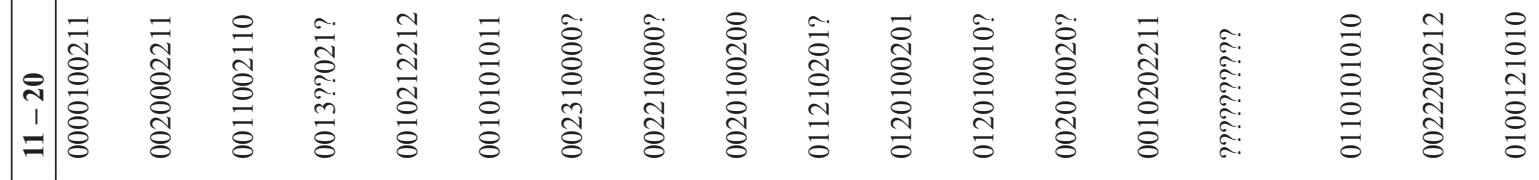

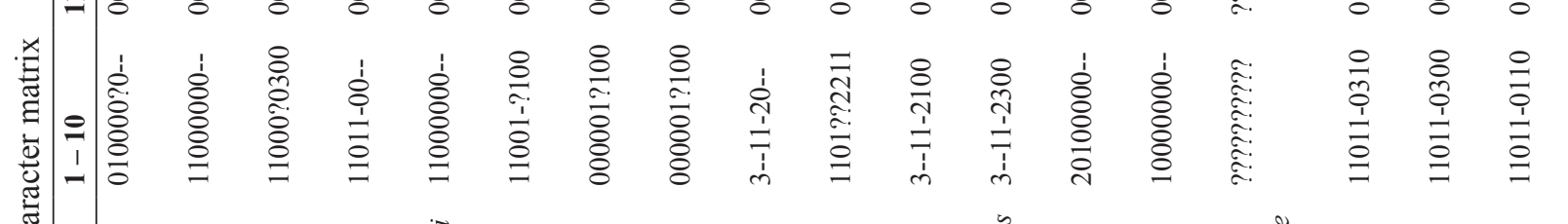

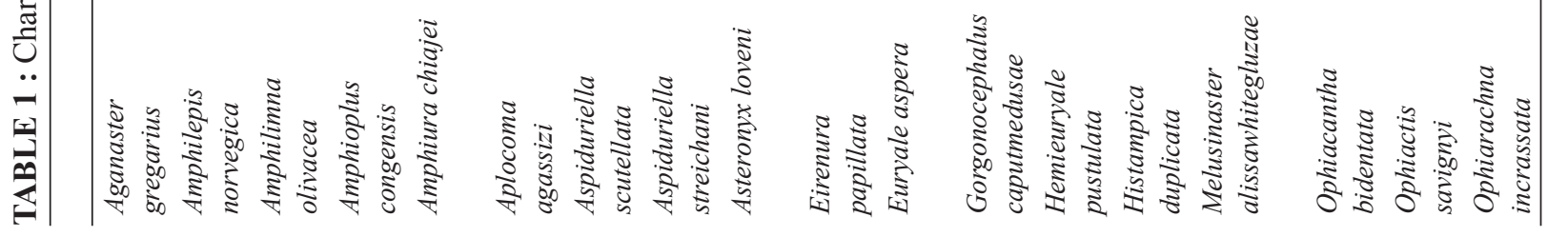




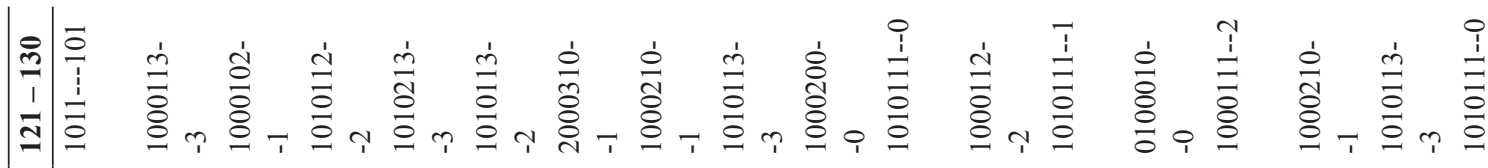

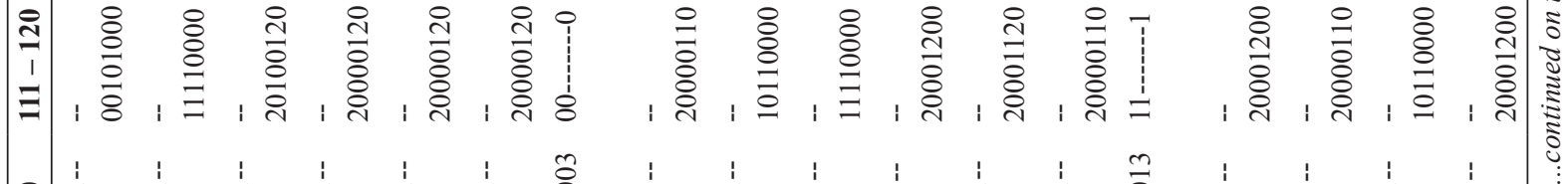

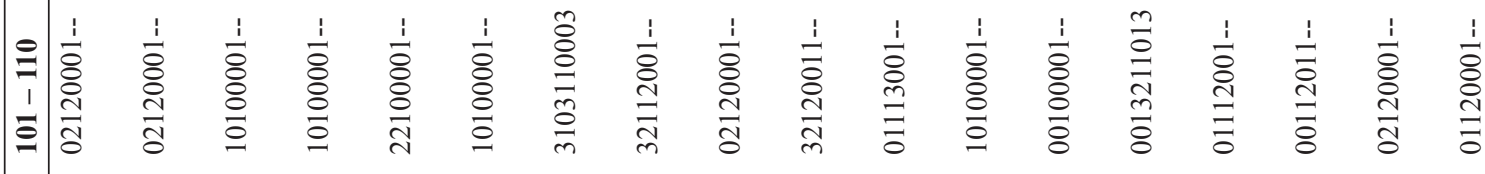

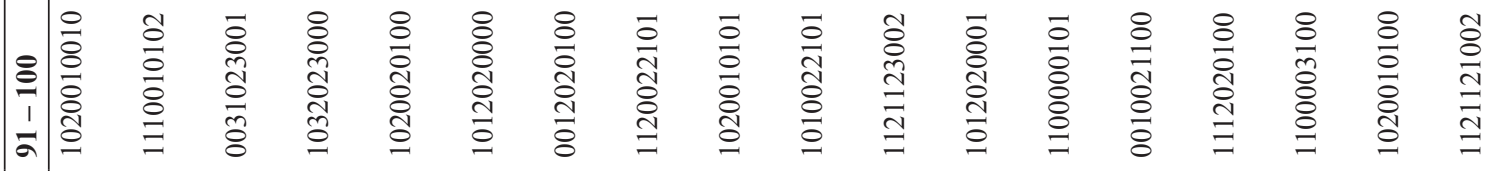

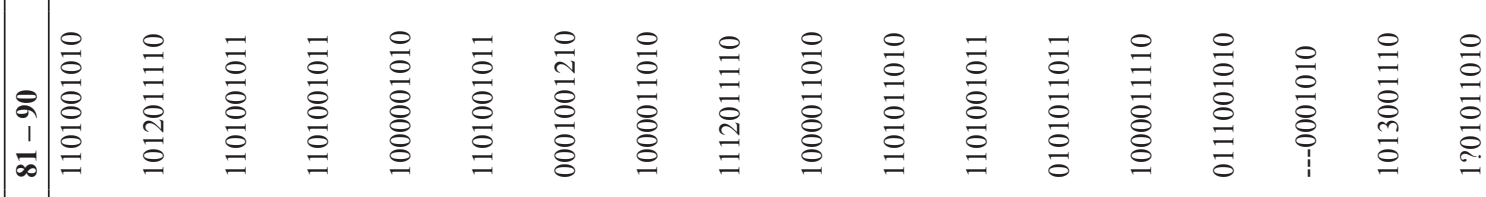

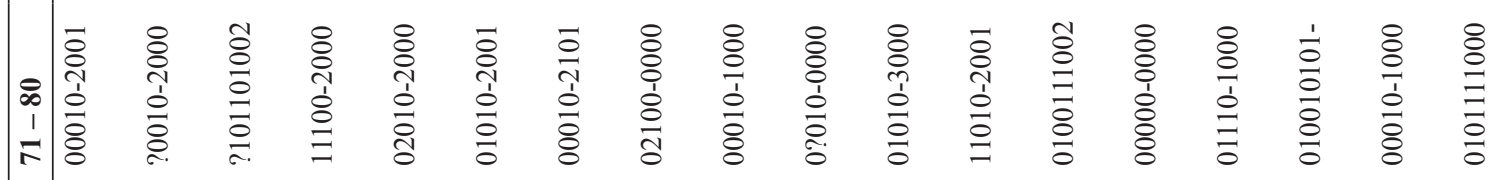

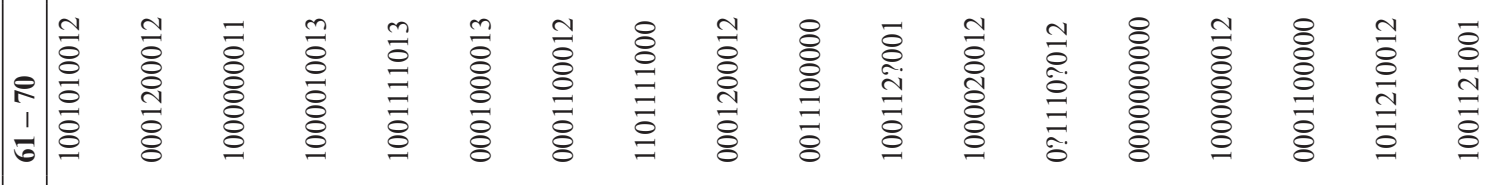

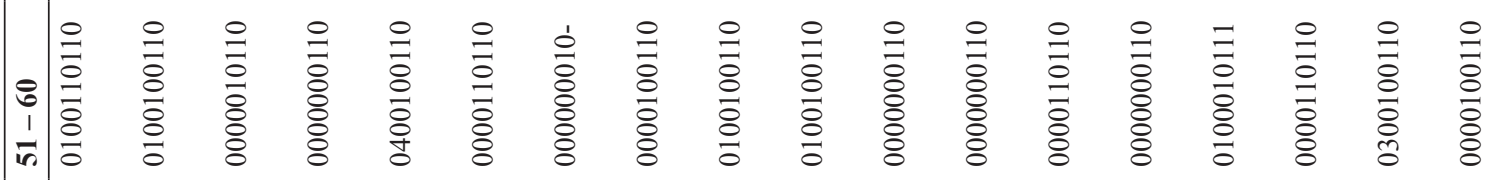

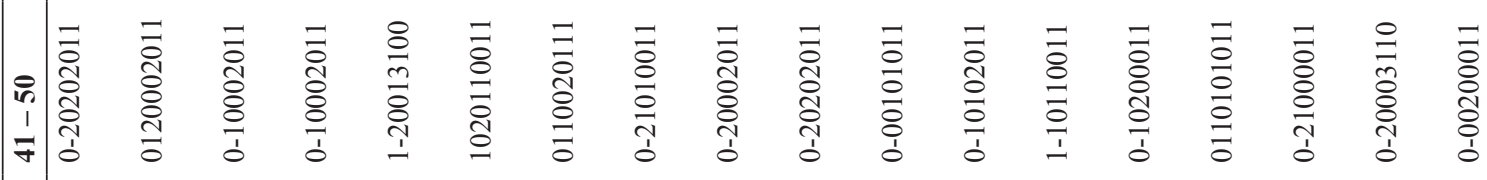

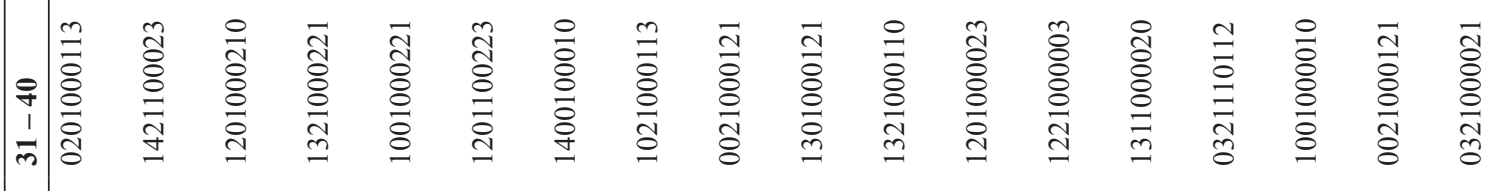

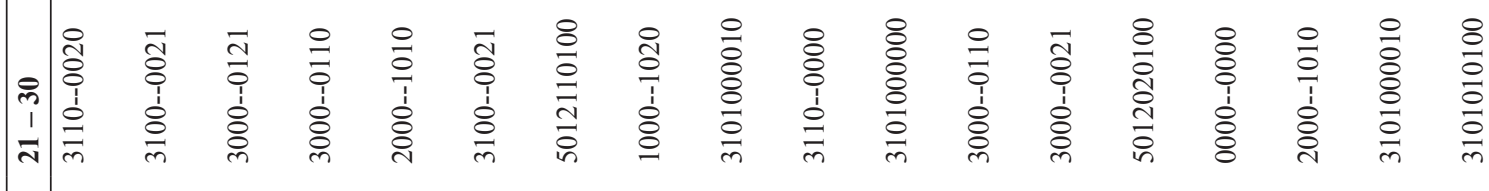

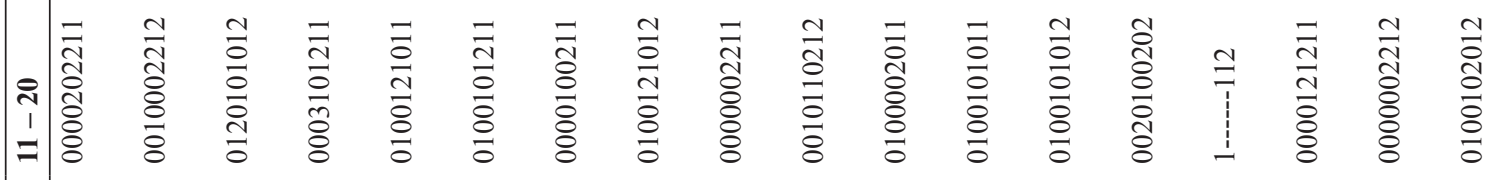

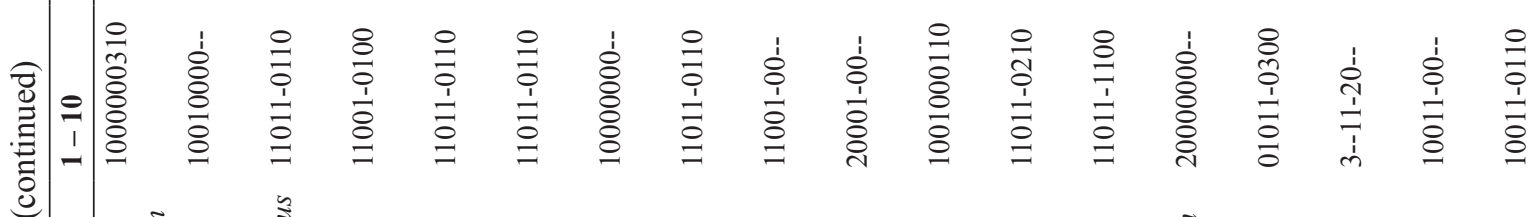

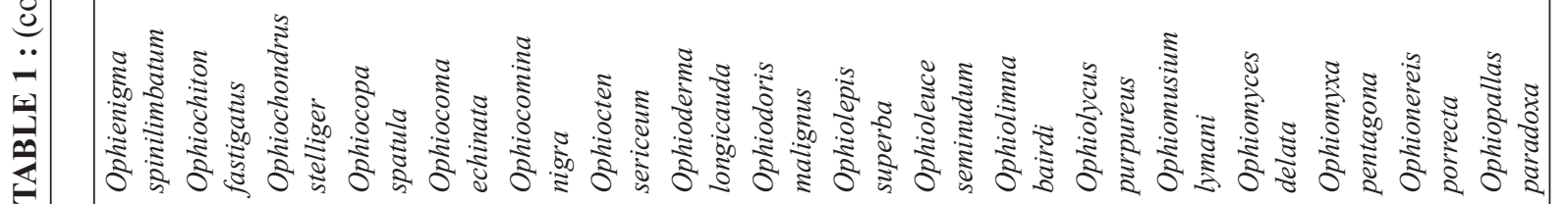




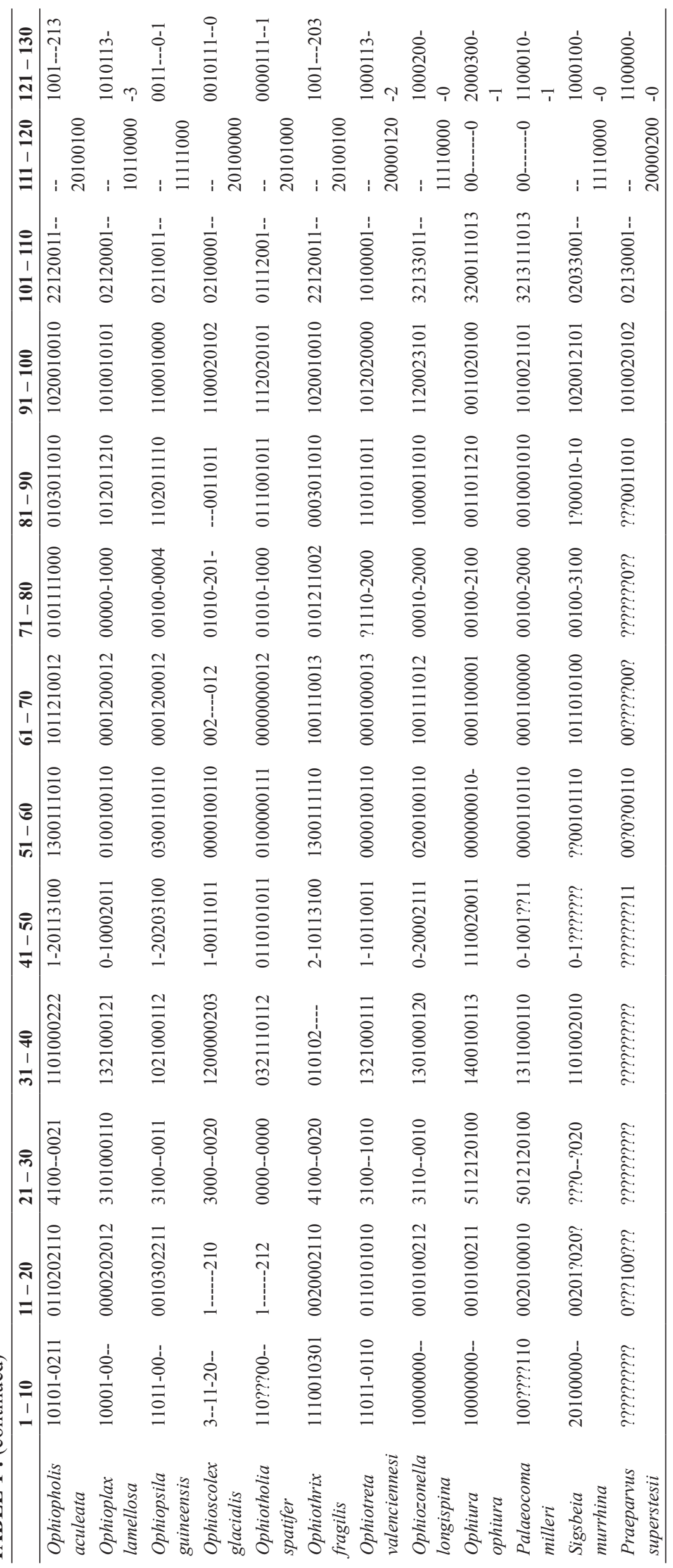


Etymology. Ophiosuperstes n. gen. is derived from the Latin adjective superstes meaning survivor, referring to the occurrence in the aftermath of the end-Permian mass extinction. Gender masculine.

Type and only species. Ophiosuperstes praeparvus sp. nov.

Diagnosis. as for the species, by monotypy.

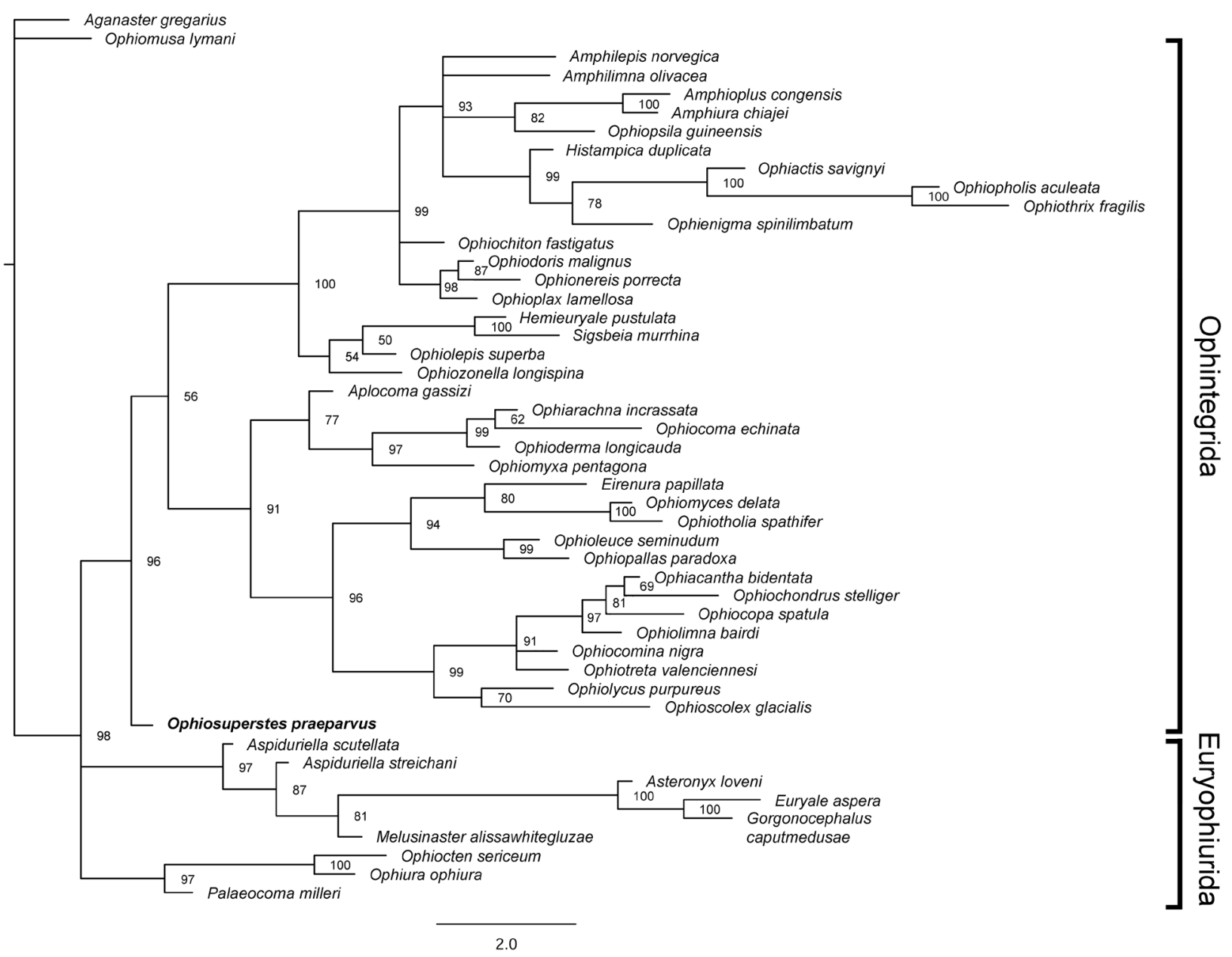

FIGURE 3: Morphology-based phylogenetic tree inferred using MrBayes, showing the position of Ophiosuperstes praeparvus gen. et sp. nov. (marked in bold). Numbers at nodes indicate posterior probabilities.

\section{Ophiosuperstes praeparvus gen. et sp. nov.}

Figs. 4-5

Etymology. praeparvus is Latin for very small or minute, as these microfossils were extracted from a small shelly fossil-style assemblage.

\section{Holotype. MnhnL OPH177}

Paratypes. MnhnL OPH178 - 190

Type locality. Lost Cabin Springs locality, southern Nevada (Maxwell et al. 2020).

Type stratum. Bed LC-18-34 within the Virgin Limestone Member of the Moenkopi Formation, Spathian, lower Triassic.

Diagnosis. Ophintegrid ophiuroid with stout lateral arm plates of rounded outline, very weak oblique elongated spur on ventro-proximal tip of outer surface, otherwise devoid of spurs or conspicuous outer surface ornamentation; with up to six small, vertical spine articulations slightly sunken into distal edge of lateral arm plate, composed of arched, shifted dorsal and ventral lobes merged at their proximal tips and encompassing the muscle and nerve openings; no sigmoidal fold; tentacle openings developed as small notches lined by a shallow groove in proximal to median lateral arm plates, and reduced to a within-plate perforation in distal lateral arm plates; ventral arm plates trapezoid; radial shields rounded isosceles triangular, without extensions or incisions. 

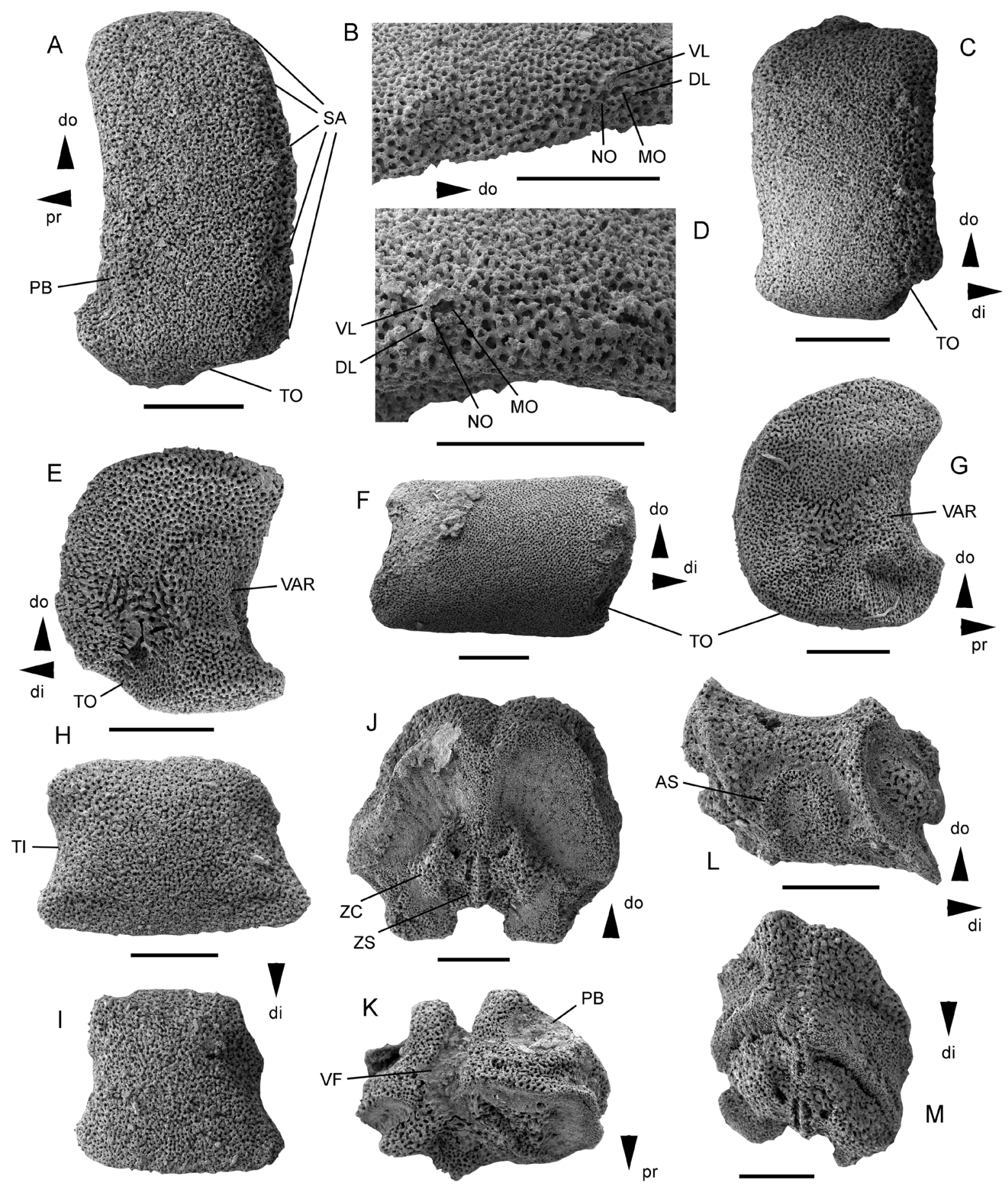

FIGURE 4: Dissociated arm plates of the ophiuroid Ophiosuperstes praeparvus gen. et sp. nov., from the Virgin Limestone Member of the Moenkopi Formation, Spathian, lower Triassic, Lost Cabin Springs locality, southern Nevada. A-B: holotype (OPH177), proximal lateral arm plate in external view (A) and with detail of spine articulations (B). C-D: paratype (OPH178), median lateral arm plate in external view $(\mathrm{C})$ and with detail of spine articulations (D). E: paratype (OPH179), median lateral arm plate in internal view. F: paratype (OPH181), distal lateral arm plate in external view. G: paratype (OPH180), median lateral arm plate in internal view. H: paratype (OPH182), proximal ventral arm plate in external view. I: paratype (OPH183), median to distal ventral arm plate in external view. J: paratype (OPH184), proximal vertebra in distal view. K: paratype (OPH185), proximal vertebra in ventral view. L: paratype (OPH186), median vertebra in lateral view. M: paratype (OPH187), median vertebra in dorso-distal view. Abbreviations: AS: articular structure; di: distal; DL: dorsal lobe; do: dorsal; MO: muscle opening; NO: nerve opening; pr: proximal; PB: podial basin; SA: spine articulations; TO: tentacle opening; VAR: vertebral articular ridge; VF: ventral furrow; VL: ventral lobe; ZC: zygocondyle; ZS: zygosphene. All scale bars equal $0.2 \mathrm{~mm}$. 

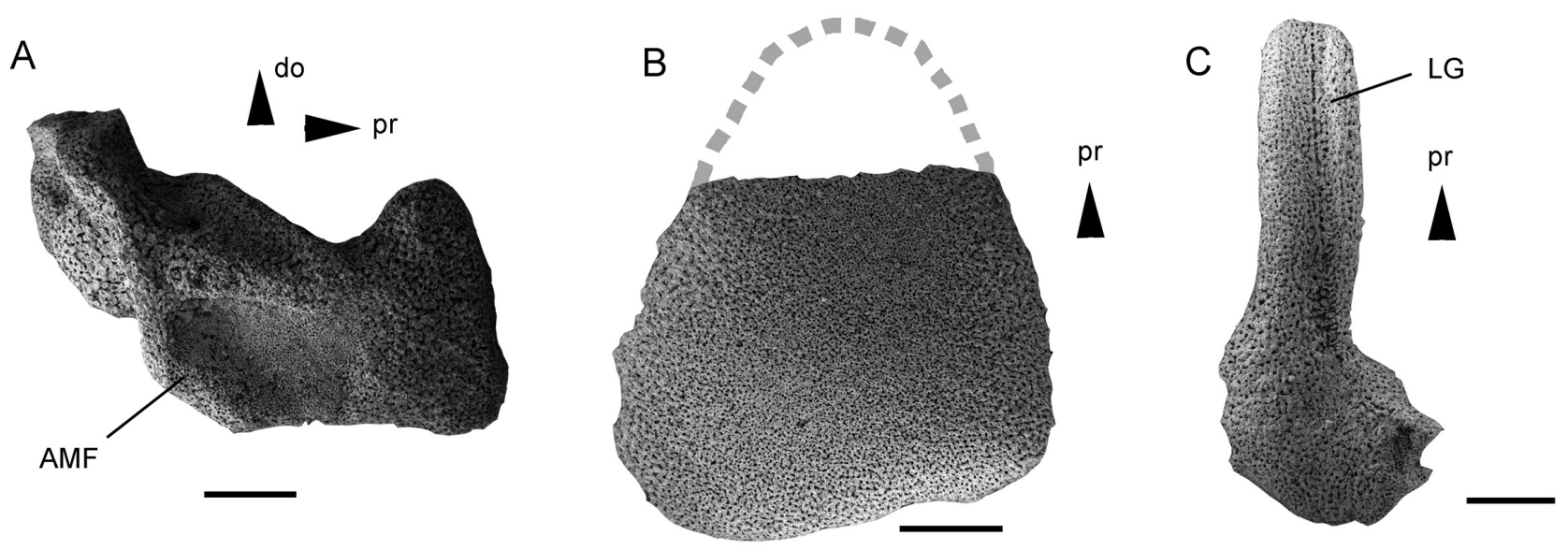

FIGURE 5: Dissociated disc plates of the ophiuroid Ophiosuperstes praeparvus gen. et sp. nov., from the Virgin Limestone Member of the Moenkopi Formation, Spathian, lower Triassic, Lost Cabin Springs locality, southern Nevada. A: paratype (OPH188), oral plate in abradial view. B: paratype (OPH189), radial shield in external view, with outline of missing proximal tip reconstructed using a dashed grey line. C: paratype (OPH190) adradial genital plate in dorsal view. Abbreviations: AMF: abradial muscle fossa; do: dorsal; LG: longitudinal groove; pr: proximal. All scale bars equal $0.2 \mathrm{~mm}$.

Description of holotype. MnhnL OPH177 is a dissociated proximal lateral arm plate of stout, rounded outline, approximately two times higher than long, with rounded dorsal and distal edges and protruding ventro-proximal portion; outer proximal edge evenly concave, lined by a relatively broad but poorly defined band of slightly more coarsely meshed stereom with a faint horizontal striation but without spurs other than a very weak oblique elongated spur on the ventro-proximal tip of the outer surface (Fig. 4A); outer surface devoid of constriction, covered by a relatively finely meshed stereom with trabecular intersections transformed into very small tubercles; five relatively small, equal-sized spine articulations along the distal edge, with a slight dorsalward increase in the size of the gaps between the spine articulations, at the same level as the outer surface stereom; spine articulations (Fig. 4B) almost vertical, composed of arched and slightly shifted dorsal and ventral lobes encompassing a small muscle opening and a slightly smaller nerve opening; ventral edge with a small but well developed tentacle notch, lined by a shallow, poorly defined groove; inner side of lateral arm plate (not figured) with a large, well-defined, single vertebral articular ridge composed of the same stereom as the remaining inner side; inner distal edge without spurs; small but clearly defined tentacle notch; no perforations discernible.

\section{Paratype supplements and variation.}

Lateral arm plates: median lateral arm plates (MnhnL OPH178 - OPH180) similar to holotype with respect to general outline, outer surface stereom (Fig. 4C), outer proximal edge, shape and position of spine articulations (Fig. 4D) and morphology of inner side (Fig. 4E, G) but with lower height/length ratio, fewer spine articulations (three to four) and smaller tentacle notch. Distal lateral arm plate (MnhnL OPH181) longer than high, of rounded rectangular outline with straight dorsal and ventral edges, with three closely-spaced spine articulations and with tentacle openings developed as within-plate perforation close to ventralmost spine articulation (Fig. 4F).

Vertebrae (MnhnL OPH184 - 187) roughly disc-shaped (proximal vertebrae, Fig. 4J, K) to cylindrical (median and distal vertebrae, Fig. 4L, M), with concave lateral saddle showing a single, tongue-shaped articular surface (Fig. $4 \mathrm{~L}$ ) with the lateral arm plate; large, straight dorsal muscle fossae and much smaller, straight ventral ones; distal face with dorsalwards converging zygocondyles and with a small zygosphene protruding only very little beyond the ventral edge of the zygocondyles (Fig. 4J); deep and broad ventral furrow with small podial basins (Fig. 4K).

Ventral arm plates (MnhnL OPH182 - 183) trapezoid, with weakly convex distal edge, concave lateral edges and narrower, rectangular proximal portion (Fig. 4H, I); no spurs or conspicuous outer surface ornamentation.

Oral plate (MnhnL OPH188) longer than high, slender, fragile, with abradial muscle fossa developed as central depression (Fig. 5A) and small adradial muscle attachment area lining ventral edge of adradio-distal articular surface. 
Radial shield (MnhnL OPH189) with proximal portion broken, rounded isosceles triangular in extrapolated outline (Fig. 5B), no signs of extensions or incisions.

Adradial genital plate (MnhnL OPH190) bar-like, with a longitudinal groove and a swollen distal end (Fig. $5 \mathrm{C})$.

Remarks. The ophiuroid remains described in the present paper include various types of skeletal components, i.e. lateral and ventral arm plates, vertebrae, oral plates, genital plates and fragmentary radial shields. The ossicles of every component type show very little variation other than the changes depending on the position within the arm (e.g. Thuy \& Stöhr 2011). In particular, the lateral arm plates all belong to the same species, as indicated by the similarities in plate proportions, outer surface ornamentation, spine articulation morphology and position, and vertebral articular structure morphology (Thuy \& Stöhr 2011). Furthermore, the various types of ossicles are of compatible size and, in some cases, show corresponding articulation surfaces, e.g. the vertebral articular ridge on the inner side of the lateral arm plates matching the lateral articular ridge of the vertebrae. We therefore conclude that all the ophiuroid remains belong to the same species.

The spine articulations of the lateral arm plates described in the present paper are composed of small muscle and nerve openings encompassed by a ventral and dorsal lobe. This configuration precludes assignment to the Euryophiurida, whose spine articulations lack dorsal and ventral lobes and have the muscle and nerve openings separated by a vertical ridge (O'Hara et al, 2018), and instead suggests assignment to the Ophintegrida. Within that superorder, affinities are not clear-cut because the lateral arm plates and the other skeletal parts lack characters that are uniquely found in one of the orders. This observation is in line with our phylogenetic estimate in which the ophiuroid described herein holds a basalmost position at the stem of the Ophintegrida.

Comparison with other fossil ophiuroids is hampered by the lack of detailed morphological analyses. Most descriptions of Triassic ophiuroids published to date are superficial and poorly illustrated, omitting important characters such as lateral arm plate microstructures that have been identified as systematically relevant (e.g. Thuy \& Stöhr 2016; O’Hara et al. 2018). Praeaplocoma hessi Broglio Loriga \& Berti Cavicchi, 1972 from the lower Triassic of Italy shares some superficial similarities with the ophiuroid described herein, in particular regarding the outline of the radial shields and the shape of the ventral arm plates. The lateral arm plates of $P$. hessi, however, are bulging. The most important difference, however, was revealed by scanning electron microscopy of newly collected specimens from the Dolomites, close to the type area of the species (Twitchett et al. 2005), showing that the spine articulations of $P$. hessi lack dorsal and ventral lobes and instead have their muscle and nerve openings separated by a vertical ridge (Fig. 6). This observation places Praeaplocoma in the superorder Euryophiurida and allows a clear distinction from the ophiuroid described herein.

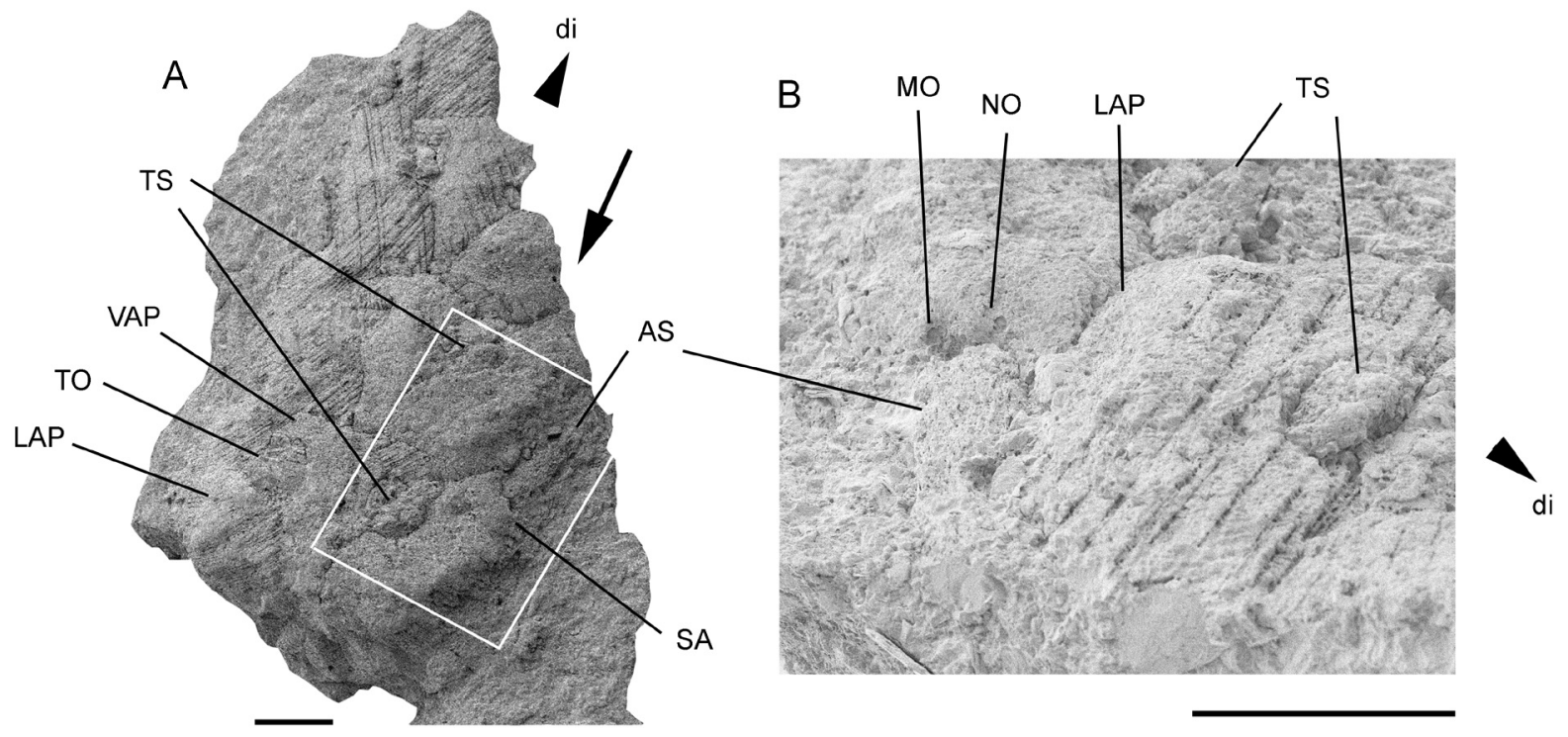

FIGURE 6: Arm fragment of Praeaplocoma hessi Broglio Loriga \& Berti Cavicchi, 1972, (MHI 1307/nnn) from the Werfen Formation, Lower Triassic, of Weißhorn, Italy. A: arm fragments in ventral view. B: detail of part marked by white rectangle in A. Abbreviations: AS: arm spine; di: distal; LAP: lateral arm plate; MO: muscle opening; NO: nerve opening; SA: spine articulation; TO: tentacle opening; TS: tentacle scale; VAP: ventral arm plate. All scale bars equal $0.2 \mathrm{~mm}$. Arrow in A indicates direction of view shown in B; refer to tentacle scales (TS) for better correspondence between A and B. 
Shoshonura brayardi Thuy, 2019 from the lower Triassic of Idaho is another confirmed basal member of the Ophintegrida. It differs from the ophiuroid described herein in the more bulging lateral arm plates and the deeper tentacle notches of the ventral arm plates. Furthermore, the spine articulations are typical of the ophintegrid order Ophiacanthida. Arenorbis squamosus (Picard, 1858) from the middle Triassic of central Europe has lateral arm plates with several spurs along the outer proximal edge, and a slightly raised distal portion with larger, unambiguously ophiodermatid-like spine articulations.

Closest similarities are shared with the middle to upper Triassic genus Aplocoma d'Orbigny, 1852, in particular with respect to the shape of the lateral arm plates. In contrast to the ophiuroid described herein, however, Aplocoma has parallel rather than dorsalward converging zygocondyles on the distal vertebral articulations, ventral arm plates with a pointed rather than straight proximal edge, lateral arm plates with a ventralwards protruding ventro-distal tip and an outer proximal edge with spurs but lacking a fine horizontal striation, and spine articulations that are oblique rather than vertical and that have a weakly developed sigmoidal fold. These characters not only differentiate Aplocoma from the ophiuroid described herein but also suggest a more derived position of that genus within the Ophintegrida. Our phylogeny corroborates this assumption and places the type species of Aplocoma, A. agassizi, at the stem of the order Ophiodermatida, albeit with low support.

Because the ophiuroid described herein differs from all other unambiguously diagnosed fossil ophiuroids, we assign it to the new genus and species Ophiosuperstes praeparvus. For the time being, we prefer to eclipse the numerous poorly diagnosed lower Triassic ophiuroid taxa (e.g. Detre \& Mihály 1987; Chen et al. 2004; Chen \& McNamara 2006), because the morphological information available for these taxa is too superficial for a meaningful comparison. A detailed re-evaluation taking into account recent progress in ophiuroid systematics is necessary in order to determine whether the respective type specimens yield sufficient morphological information for an unambiguous diagnosis. Therefore, rather than extrapolating or perpetuating these questionable taxa, we prefer to introduce a new, unambiguously diagnosed taxon as a basis for future comparison.

\section{Discussion}

The results of the phylogenetic estimate suggest that Ophiosuperstes praeparvus gen. et sp. nov. holds a basalmost position within the Ophintegrida, which is one of the two superorders of the living Ophiuroidea (O'Hara et al. 2017, 2018). For a long time, the basal radiation of the modern ophiuroids was supposed to have taken place in the Early Triassic, following an extreme bottleneck at the end-Permian mass extinction (e.g. Smith et al. 1995). Molecular and palaeontological data published in recent years, however, show that the diversification of the modern ophiuroids was well under way long before the end-Permian mass extinction (e.g. O'Hara et al. 2014, 2017; Thuy et al. 2015, 2019). The existence of coeval but more derived ophiuroids such as Shoshonura brayardi Thuy, 2019 suggests that Ophiosuperstes praeparvus gen. et sp. nov. is probably a persisting member of a more ancient stem ophintegrid group.

The discovery of Ophiosuperstes praeparvus gen. et sp. nov. was only possible thanks to the highly unusual preservation of its fossils. In fact, elemental composition analysis using EDS confirmed that the skeletal elements are composed of calcium phosphate, implying that the original high-Mg calcite of the ophiuroid skeleton was completely replaced by apatite. Thanks to phosphatization, the ophiuroid ossicles were left unscathed by the dissolution of the hard, fossiliferous limestone. There has been some debate surrounding the mechanisms behind phosphatization during this time period, in particular phosphogenesis driven by high-energy mixing events (Freeman et al. 2013; Milam et al. 2017) versus phosphatization occurring in beds with low sedimentation rates and/or sedimentary hiatuses (Freeman et al. 2019,). Maxwell et al. (2020) observed a link between small shell size and phosphatization, and suggest phosphatization resulted from the combination of warm pore water with low levels of oxygen and the small particle size of the ophiuroid fragments.

Generally, the original high-Mg calcite of echinoderm ossicles recrystallizes into low-Mg calcite during diagenesis, filling the stereom pores and transforming the original porous ossicle into a massive calcite crystal (Gorzelak et al. 2016). The fact that stereom pores are preserved to the finest detail even inside the skeletal plates suggests either that phosphatization took place before calcite recrystallisation, or that recrystallisation exceptionally led to a perfect textural stereom preservation. This is in line with previous reports of phosphatized echinoderms, where excellent stereom preservation prevailed (Pisera 1994; Svensson 1999). To our knowledge, this is the first case of an unambiguous phosphatized ophiuroid. 


\section{Acknowledgments}

We thank E. Smith, O. Leadbetter, T. McGann, R. Revolorio Keith, M. Slaymaker and A. Hagen for help in field collection, and we acknowledge C. Stark for both field assistance and initial analysis of the samples. We thank Smith Geosciences for generous funding for this project, and C. Sumrall for linking team members in this project. We thank Hans Hagdorn (Ingelfingen, Germany) who provided specimens of Praeaplocoma hessi for comparison. Finally, we thank Sabine Stöhr, Fred Hotchkiss and an anonymous reviewer whose comments greatly improved an earlier version of this manuscript.

\section{Author contributions}

VM and SBP collected the material and processed the samples; BT and VM picked the skeletal remains and produced the scanning electron microscope images; BT performed the phylogenetic analysis; VM and SBP performed the elemental composition analysis; VM and BT compiled the figures; BT took the lead in writing the manuscript; all authors contributed to the manuscript.

\section{References}

Botting, J.P., Brayard, A. \& The Paris Biota Team (2019) A late-surviving Triassic protomonaxonid sponge from the Paris Biota, Idaho, USA. Geobios, 54, 5-11.

https://doi.org/10.1016/j.geobios.2019.04.006

Brayard, A., Jenks, J.F., Bylund, K.G. \& The Paris Biota Team. (2019) Earliest Spathian ammonoids and nautiloids from the Paris Biota and Bear Lake area: significance for regional-to-global stratigraphy and correlation. Geobios, 54, 13-36. https://doi.org/10.1016/j.geobios.2019.04.007

Brayard, A., Krumenacker, L.J., Botting, J.P., Jenks, J.F., Bylund, K.G., Fara, E., Vennin, E., Olivier, N., Goudemand, N., Saucède, T., Charbonnier, S., Romano, C., Doguzhaeva, L., Thuy, B., Hautmann, M., Stephen, D.S., Thomazo, C. \& Escarguel, G. (2017) Unexpected Early Triassic marine ecosystem and the rise of the Modern evolutionary fauna. Science Advances, 3, e1602159. https://doi.org/10.1126/sciadv.1602159

Broglio Loriga, C. \& Berti Cavicchi, A. (1972) Praeaplocoma hessi n. gen., n. sp., un Ofiura del Werfeniano (Trias Inferiore) del Gruppo della Costabella, Dolomiti. Memorie Geopaleontologiche dell'Universita di Ferrara, 2 (1), 185-197.

Charbonnier, S., Brayard, A. \& The Paris Biota Team (2019) New thylacocephalans from the Early Triassic Paris Biota (Idaho, U.S.A.). Geobios, 54, 37-43. https://doi.org/10.1016/j.geobios.2019.04.005

Chen, Z.Q. \& Mcnamara, K.J. (2006) End-Permian extinction and subsequent recovery of the Ophiuroidea (Echinodermata). Palaeogeography, Palaeoclimatology, Palaeoecology, 236, 321-344. https://doi.org/10.1016/j.palaeo.2005.11.014

Chen, Z.Q., Shi, G.R. \& Kaiho, K. (2004) New ophiuroids from the Permian/Triassic boundary beds of South China. Palaeontology, 47, 1301-1312. https://doi.org/10.1111/j.0031-0239.2004.00406.x

Detre, C. \& Mihály, S. (1987) Két Újabb Ophiuroida Lelet A Balaton-Felvidék Triászából. A Magyar Állami Földtani Intézet Évi Jelentése Az, 1985, 449-452.

Doguzhaeva, L.A., Brayard, A., Goudemand, N., Krumenacker, L.J., Jenks, J.F., Bylund, K.G., Fara, E., Olivier, N., Vennin, E. \& Escarguel, G. (2018) An Early Triassic gladius associated with soft tissue remains from Idaho, USA-a squid-like coleoid cephalopod at the onset of Mesozoic Era. Acta Palaeontologica Polonica, 63, 341-355. https://doi.org/10.4202/app.00393.2017

d’Orbigny, A.D. (1852) s.n. In: Cours élémentaire de paléontologie et de géologie stratigraphiques. 2 (2). Masson, Paris, pp. 381-849.

Erwin, D.H. (1993) The Great Paleozoic Crisis: life and death in the Permian. Columbia University Press, New York, New York, 327 pp.

Freeman, R.L., Dattilo, B.F. \& Brett, C.E. (2019) An integrated stratinomic model for the genesis and concentration of ,small shelly fossil ' - style phosphatic microsteinkerns in not - so - exceptional conditions. Palaeogeography, Palaeoclimatology, Palaeoecology, 535, 109344. https://doi.org/10.1016/j.palaeo.2019.109344

Freeman, R.L., Dattilo, B.F., Morse, A., Blair, M., Felton, S. \& Pojeta, J. (2013) The ,Curse Of Rafinesquina:‘ negative taphonomic feedback exerted by strophomenid shells on storm - buried Lingulids In The Cincinnatian Series (Katian, 
Ordovician) of Ohio. Palaois, 28, 359-372.

https://doi.org/10.2110/palo.2012.p12-094r

Gorzelak, P., Krzykawski, T. \& Stolarski, J. (2016) Diagenesis of echinoderm skeletons: Constraints on paleoseawater Mg/Ca reconstructions. Global and Planetary Change, 144, 142-157.

https://doi.org/10.1016/j.gloplacha.2016.07.010

Hagdorn, H. (2018) Slipped through the bottleneck: Lazarechinus mirabeti gen. et sp. nov., a Paleozoic-like echinoid from the Triassic Muschelkalk (late Anisian) of East France. Paläontologische Zeitschrift, 92, 267-282. https://doi.org/10.1007/s12542-017-0393-1

Hoffmann, R., Hautmann, M., Wasmer, M. \& Bucher, H. (2013) Palaeoecology of the Spathian Virgin Formation (Utah, USA) and Its Implications for the Early Triassic Recovery. Acta Palaeontologica Polonica, 58, 149-173.

Huelsenbeck, J.P. \& Ronquist, F. (2001) MRBAYES: Bayesian inference of phylogenetic trees. Bioinformatics, 17, 754-755. https://doi.org/10.1093/bioinformatics/17.8.754

Lewis, P.O. (2001) A likelihood approach to estimating phylogeny from discrete morphological character data. Systematic Biology, 50, 913-925. https://doi.org/10.1080/106351501753462876

Marzolf, J.E. (1993) Palinspastic reconstruction of early Mesozoic sedimentary basins near the latitude of Las Vegas; implications for the early Mesozoic Cordilleran cratonal margin. In: Dunne, G.C. \& McDougall, K. (Eds.), Mesozoic Paleogeography of the Western United States, II, SEPM, Book 71, pp 433-462.

Matsumoto, H. (1915) A new classification of the Ophiuroidea: with description of new genera and species. Proceedings of the Academy of Natural Sciences of Philadelphia, 68, 43-92.

Maxwell, V., Thuy, B. \& Pruss, S.B. (2020) An Early Triassic small shelly fossil - style assemblage from the Virgin Limestone Member, Moenkopi Formation, western United States. Lethaia, 54, 368-377. https://doi.org/10.1111/let.12409

Milam, M.J., Meyer, D.L., Datillo, B.F. \& Hunda, B.R. (2017) Taphonomy of an Ordovician crinoid lagerstätte from Kentucky. Palaios, 32, 166-180. https://doi.org/10.2110/palo.2016.048

O‘Hara, T.D., Hugall, A.F., Thuy, B. \& Moussalli, A. (2014) Phylogenomic Resolution of the Class Ophiuroidea Unlocks a Global Microfossil Record. Current Biology, 24, 1874-1879. https://doi.org/10.1016/j.cub.2014.06.060

O‘Hara, T.D., Hugall, A.F., Thuy, B., Stöhr, S. \& Martynov, A.V. (2017) Restructuring higher taxonomy using broad-scale phylogenomics: The living Ophiuroidea. Molecular Phylogenetics and Evolution, 107, 415-430. https://doi.org/10.1016/j.ympev.2016.12.006

O`Hara, T.D., Stöhr, S., Hugall, A.F., Thuy, B. \& Martynov, A. (2018) Morphological diagnoses of higher taxa in Ophiuroidea (Echinodermata) in support of a new classification. European Journal of Taxonomy, 416, 1-35. https://doi.org/10.5852/ejt.2018.416

Picard, E. (1858) Über den Keuper bei Schlotheim in Thüringen und seine Versteinerungen. Zeitschrift für die Gesamten Naturwissenschaften, 11, 425-436.

Pisera, A. (1994) Echinoderms of the Mójcza Limestone. In: Dzik, J., Olempska, E. \& Pisera, A. (Eds.) Ordovician carbonate platform ecosystem of the Holy Cross Mountains, Poland. Palaeontologia Polonica, Warsaw, 53, pp. 283-307.

Poborski, S.J. (1954) Virgin Formation (Triassic) of the St. George, Utah, area. Geological Society of America Bulletin, 65, 971-1006. https://doi.org/10.1130/0016-7606(1954)65[971:VFTOTS]2.0.CO;2

Pruss, S.B., Fraiser, M.L. \& Bottjer, D.J. (2004) Proliferation of Early Triassic wrinkle structures: implications for environmental stress following the end - Permian mass extinction. Geology, 35, 461-465. https://doi.org/10.1130/G20354.1

Pruss, S.B. \& Bottjer, D.J. (2004) Late Early Triassic microbial reefs of the western United States: a description and model for their deposition in the aftermath of the end-Permian mass extinction, Palaeogeography, Palaeoclimatology, Palaeoecology, 211, 127-37. https://doi.org/10.1016/j.palaeo.2004.05.002

Pruss, S.B., Corsetti, F.A. \& Bottjer, D.J. (2005) The unusual sedimentary rock record of the Early Triassic: a case study from the southwestern United States. Palaeogeography, Palaeoclimatology, Palaeoecology, 222, 33-52. https://doi.org/10.1016/j.palaeo.2005.03.007

Reif, D.M. \& Slatt, R.M. (1979) Red bed members of the Lower Triassic Moenkopi Formation, southern Nevada; sedimentology and paleogeography of a muddy tidal flat deposit. Journal of Sedimentary Petrology, 49, 869-889. https://doi.org/10.1306/212F7865-2B24-11D7-8648000102C1865D

Romano, C., Argyriou, T., Krumenacker, L.J. \& The Paris Biota Team. (2019) Chondrichthyan teeth from the Early Triassic Paris Biota (Bear Lake County, Idaho, USA). Geobios, 54, 63-70. https://doi.org/10.1016/j.geobios.2019.04.001

Saucède, T., Vennin, E., Fara, E., Olivier, N. \& The Paris Biota Team. (2019) A new holocrinid (Articulata) from Idaho (USA) highlights the high diversity of Early Triassic crinoids. Geobios, 54, 45-53.

https://doi.org/10.1016/j.geobios.2019.04.003 
Schubert, J.K. \& Bottjer, D.J. (1995) Aftermath of the Permian - Triassic mass extinction event: paleoecology of Lower Triassic carbonates in the Western USA. Palaeogeography, Palaeoclimatology, Palaeoecology, 116, 1-39. https://doi.org/10.1016/0031-0182(94)00093-N

Sepkoski, J.J. Jr. (1981) A factor analytic description of the Phanerozoic marine fossil record. Paleobiology, 7, $36-53$. https://doi.org/10.1017/S0094837300003778

Smith, A.B., Paterson, G.L.J. \& Lafay, B. (1995) Ophiuroid phylogeny and higher taxonomy: morphological, molecular and palaeontological perspectives. Zoological Journal of the Linnean Society, 114, 213-243. https://doi.org/10.1006/zjls.1995.0024

Stöhr, S., O‘Hara, T.D. \& Thuy, B. (2012) Global diversity of Ophiuroidea. PLOS ONE, 7 (3), e31940. https://doi.org/10.1371/journal.pone.0031940

Svensson, A.M. (1999) Phosphatized echinoderm remains from upper Lower Ordovician strata of northern Öland, Sweden : preservation, taxonomy and evolution. Examensarbete I geologi vid Lunds Universitet, Historisk geologi och paleontologi, $105,1-60$.

Thompson, J.R., Hu, S., Zhang, Q.Y., Petsios, E., Cotton, L.J., Huang, J.Y., Zhou, C., Wen, W. \& Bottjer, D.J. (2018) A new stem group echinoid from the Triassic of China leads to a revised macroevolutionary history of echinoids during the end-Permian mass extinction. Royal Society Open Science, 5, 171548. https://doi.org/10.1098/rsos.171548

Thuy, B., Escarguel, G. \& The Paris Biota Team. (2019) A new brittle star (Ophiuroidea: Ophiodermatina) from the Early Triassic Paris Biota (Bear Lake County, Idaho, USA). Geobios, 54, 55-61. https://doi.org/10.1016/j.geobios.2019.04.004

Thuy, B., Hagdorn, H. \& Gale, A.S. (2017) Paleozoic echinoderm hangovers: Waking up in the Triassic. Geology, 45 (6), 531-534. https://doi.org/10.1130/G38909.1

Thuy, B., Kutscher, M. \& Bartosz, P.J. (2015) A new brittle star from the early Carboniferous of Poland and its implications on Paleozoic modern-type ophiuroid systematics. Acta Palaeontologica Polonica, 60, 923-929. https://doi.org/10.4202/app.00093.2014

Thuy, B. \& Numberger-Thuy, L.D. (2021) Brittlestar diversity at the dawn of the Jenkyns Event (early Toarcian Oceanic Anoxic Event): new microfossils from the Dudelange drill core, Luxembourg. Geological Society, London, Special Publications, $514,83-119$. https://doi.org/10.1144/SP514-2021-3

Thuy, B. \& Stöhr, S. (2011) Lateral arm plate morphology in brittle stars (Echinodermata: Ophiuroidea): new perspectives for ophiuroid micropalaeontology and classification. Zootaxa, 3013, 1-47. https://doi.org/10.11646/zootaxa.3013.1.1

Thuy, B. \& Stöhr, S. (2016) A new morphological phylogeny of the Ophiuroidea (Echinodermata) accords with molecular evidence and renders microfossils accessible for cladistics. PLOS ONE, 11 (5), e0156140. https://doi.org/10.1371/journal.pone.0156140

Thuy, B. \& Stöhr, S. (2018) Unravelling the origin of the basket stars and their allies (Echinodermata, Ophiuroidea, Euryalida). Scientific Reports, 8, 8493. https://doi.org/10.1038/s41598-018-26877-5

Twitchett, R.J., Feinberg, J.M., O‘Connor, D.D., Alvarez, W. \& McCollum, L.B. (2005) Early Triassic Ophiuroids: their paleoecology, taphonomy and distribution. Palaios, 20, 213-223. https://doi.org/10.2110/palo.2004.p04-30

Twitchett, R.J. \& Oji, T. (2005) Early Triassic recovery of echinoderms. Comptes Rendus Paleovol, 4, 531-542. https://doi.org/10.1016/j.crpv.2005.02.006

Wright, A.M. \& Hillis, D.M. (2014) Bayesian Analysis Using a Simple Likelihood Model Outperforms Parsimony for Estimation of Phylogeny from Discrete Morphological Data. PLoS ONE, 9, e109210.

https://doi.org/10.1371/journal.pone.0109210 